\title{
PROGRAMA DE LEITORADO DO BRASIL: discussões sobre o perfil profissional do leitor
}

Leilane Morais Oliveira

Universidade de São Paulo

\section{RESUMO}

Localizado no âmbito dos estudos relativos às políticas linguísticas externas (CALVET, 2007), este artigo se propõe a apresentar uma análise do perfil profissional, em termos de formação acadêmica, de sujeitos que atuaram junto ao Programa de Leitorado do Brasil entre 2010 e 2014. Para isso, dados inéditos, coletados mediante pesquisa documental no Arquivo Nacional do Palácio do Itamaraty, são apresentados e discutidos. Informações, obtidas pela aplicação de questionário aos leitores estudados e por entrevista realizada com o antigo ministro-diretor do Departamento Cultural do Ministério das Relações Exteriores, também fazem parte da problematização e permitem relacionar a formação dos leitores a uma discussão mais ampla sobre a profissionalização do docente de línguas no Brasil. A partir disso, o estudo também menciona a baixa oferta de licenciaturas na área de Letras/Ensino de Português para Falantes de Outras Línguas (PFOL) e a não exigência, por parte da Capes e do Ministério das Relações Exteriores, de uma formação específica em Letras para candidatura ao Programa de Leitorado, o que permite enfatizar, com vistas ao andamento futuro desse planejamento linguístico, que os leitores devem ser professores/profissionais formados na área de línguas.

PALAVRAS-CHAVE: Programa de Leitorado; Políticas Linguísticas; Brasil. 


\section{Introdução}

A história recente do Brasil, embora oscile entre crises e a posição de economia emergente, parece mostrar que o país vive uma experiência linguística mais autônoma, visto que se ocupa do desenvolvimento de ações relativas à modificação da visão internacional de sua cultura $\mathrm{e}$ língua oficial, sobretudo por meio de seu ensino em diferentes partes do globo.

Exemplos disso são os planejamentos linguísticos ${ }^{1}$ (CALVET, 2007) executados pela Divisão de Promoção da Língua Portuguesa (DPLP), órgão subordinado ao Ministério das Relações Exteriores e responsável pelo desenvolvimento de educação linguístico-cultural em solo internacional, a qual se estabelece mediante o funcionamento de Institutos e Centros Culturais, bem como do Programa de Leitorado.

O objetivo deste artigo, diante da realidade apresentada, é caracterizar o perfil profissional de um grupo de sujeitos (aqui chamados de leitores) $)^{2}$ que, entre os anos de 2010 e 2014, atuou junto ao Programa de Leitorado brasileiro. Para contemplar esse objetivo, dados inéditos, ligados à pesquisa documental realizada no Arquivo Nacional do Palácio do Itamaraty e aos currículos de ex-leitores ${ }^{3}$, são apresentados e discutidos. Informações obtidas, pela aplicação de questionário aos sujeitos estudados e por entrevista realizada com o antigo ministro-diretor do Departamento Cultural do Ministério das Relações Exteriores, também fazem parte da problematização e permitem relacionar a formação dos leitores a uma discussão mais ampla sobre a profissionalização do docente de línguas no Brasil.

Assim, o artigo está organizado a partir da seguinte ordem: primeiramente, apresenta-se uma discussão sobre o Programa de Leitorado e as bases legais que o regem, o que é seguido pela caracterização do perfil de profissional dos leitores, bem como por algumas considerações relacionadas à necessária profissionalização do professor de línguas, o que se dá em função de ressaltar motivos que levem a exigência de uma formação específica na área das Letras a se tornar parte dos futuros processos seletivos de leitores.

\section{Sobre o Programa de Leitorado do Brasil}

O Programa de Leitorado, iniciado na década de 1960, tem o objetivo principal de difundir a cultura e o português brasileiros em univer- 
sidades do exterior, por meio da atuação de professores (chamados de leitores) que são contratados por um período de dois anos - prorrogáveis por mais dois. De modo geral, o Programa de Leitorado concentra seus esforços em regiões prioritárias à diplomacia nacional ${ }^{4} \mathrm{e}$, neste sentido, torna-se um planejamento linguístico altamente estratégico ao governo brasileiro.

Quanto às exigências relativas à ocupação do cargo de leitor, o governo brasileiro estabeleceu, em 1999, uma portaria que as regulamentava. Nela, se previa que o leitor deveria ser um "professor universitário que se dedica ao ensino do idioma Português falado no Brasil, da cultura e da literatura brasileiras". Em 20 de março de 2006, entretanto, a Portaria Interministerial n. ${ }^{\circ} 01$ revogou a publicada em 1999 e, além de formalizar a CAPES (Coordenação de Aperfeiçoamento de Pessoal de Nível Superior) como órgão responsável pelo processo seletivo do programa, simplificou a questão, dizendo que o leitor era tão somente um professor universitário de nacionalidade brasileira.

Atualmente, os leitores são contratados sob o regime de convênio ${ }^{5}$ - entre o Ministério das Relações Exteriores e as universidades estrangeiras que sediam o programa - conforme consta no decreto $n .^{\circ} 8.180$ de 30 de dezembro de 2013. A CAPES informa, em relação ao processo seletivo, que ele realiza

verificação do cumprimento de interstício em relação ao exercício de anterior função de Leitor brasileiro, verificação da consistência documental, análise do mérito científico da candidatura, considerando o perfil acadêmico-profissional requerido pela universidade estrangeira (...) e seleção final. ${ }^{6}$

Estas colocações permitem observar que o processo seletivo dos leitores baseia-se em requisitos consideravelmente amplos, os quais refletem antes as exigências apresentadas pelas universidades estrangeiras do que em padrões estabelecidos previamente pelo próprio Itamaraty e/ ou pela Capes, como também foi relatado em estudo de Nóbrega (2016).

Alguns autores (SÁ, 2009; OLIVEIRA, 2010), neste sentido, argumentam que o Estado brasileiro carece de maior coesão em relação à gestão geral de suas políticas linguísticas externas. Referindo-se especificamente aos Leitorados, Sá (2009, p. 34) diz que

não há no momento um protocolo de cooperação comum a toda rede de Leitorados. Dito de outra forma, existe uma ausência de redes in- 
ternas (conhecimento do trabalho do Leitor anterior) e externas (contatos com outros Leitorados). De uma maneira geral, o resultado é uma condição (...) de condições de trabalho isoladas e, por vezes, muito distintas. A ausência de redes também resulta em diferentes entendimentos dos Leitores sobre o seu próprio trabalho e até mesmo sobre o que é o Leitorado.

Embora de extrema importância, os Leitorados ainda não haviam sido, até bem pouco tempo, pauta da comunidade científica brasileira, o que, somado a outros fatores, contribuiu para que o cenário descrito por Sá (2009) permanecesse basicamente inalterado. Sendo assim, o presente estudo desenvolve, na sequência, uma discussão de dados ligados a esclarecimentos sobre o perfil profissional de ex-leitores do Brasil.

\section{Qual é o perfil profissional dos leitores brasilei- ros espalhados pelo mundo?}

Quando a pauta da discussão gira em torno dos leitores brasileiros, algumas perguntas de ordem identitária ainda se impõem: quem são esses profissionais? Qual é âmbito de sua formação profissional? O que os caracteriza como grupo? O advérbio "ainda" é utilizado porque a literatura científica demonstra ser pouco o que se sabe sobre o leitor brasileiro enquanto sujeito atuante no mundo do trabalho (SÁ, 2009; OLIVEIRA, 2010, FERREIRA, 2014).

Indiferentemente ao fato de ocuparem lugar de centralidade no quadro das políticas ligadas à promoção e internacionalização da língua $\mathrm{e}$ da cultura do Brasil, já que suas ações desempenham um papel de extrema importância no interior de quadros institucionais universitários e, até mesmo, em organismos oficiais, os leitores e suas características profissionais são pouco claras.

Isso se deve, em grande medida, às particularidades relativas ao desenvolvimento de suas atividades laborais, as quais, por se darem em diferentes contextos geográficos e sociais, apresentam grande risco de dispersão em sua gestão. A indefinição do perfil profissional também se deve, não há dúvida, ao processo de recrutamento dos leitores, que segue muitos critérios impostos pelas universidades estrangeiras e são, por isso, consideravelmente divergentes.

Bruchet (2012) realizou um estudo sobre os leitores do governo francês e esclareceu que, em sua maioria, eles possuem o título de mestre e/ou são doutorandos ou recém-doutores. Segundo o autor, os leito- 
res franceses são geralmente formados no domínio das Letras e Ciências Humanas (principalmente em Línguas Estrangeiras, Línguas Modernas, História e Filosofia), encontrando-se entre o fim dos estudos e a entrada no mundo do trabalho.

Em relação aos leitores do Brasil, observou-se que a maior parte dos sujeitos pesquisados possui formação inicial na grande área das Letras, incluindo licenciaturas e bacharelados em língua portuguesa e suas literaturas, em línguas estrangeiras e em Linguística, como é possível constatar no gráfico I:

Gráfico I - Formação dos leitores em nivel de graduação.

\section{Formação dos leitores - cursos de graduação}

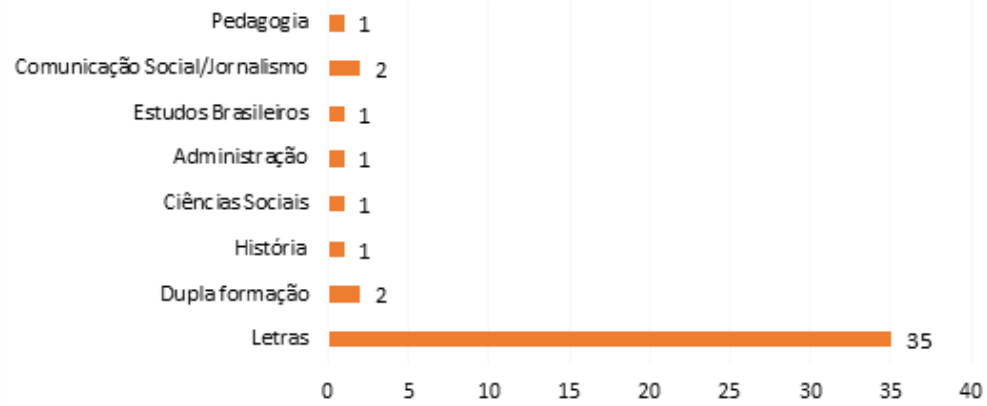

Fonte: elaborado pela autora.

Dentre os 35 leitores que cursaram Letras, apenas um tem formação específica em Português do Brasil como Segunda Língua, curso realizado na Universidade de Brasília, e três graduaram-se em Letras fora do país: um na França, um na Itália e outro na Bolívia. Além disso, desses 35, dois possuem dupla formação: além de Letras, um é formado também em Comunicação Social e outro em Pedagogia. Do total de 42 leitores, um se formou na década de 1970, oito nos anos de 1980, sete nos anos de 1990 e $26-62 \%$ do total - nos anos 2000 .

Diante desses dados, buscou-se verificar quais foram as exigências apresentadas, pelos editais de recrutamento de leitores publicados entre 2010 e 2014, em relação à formação profissional mínima dos candidatos. O quadro I esclarece, neste sentido, que a variação foi realmente muito pequena?: 
Quadro I - Requisitos para a candidatura dos leitores, em relação à formação mínima exigida, segundo os editais de seleção dos anos de 2010 a 2014.

\begin{tabular}{|c|c|}
\hline Edital $n^{\circ}$ & $\begin{array}{l}\text { Requisitos para candidatura em relação à formação } \\
\text { (item e exigência) }\end{array}$ \\
\hline $023 / 2010$ & $\begin{array}{l}\text { 2.1.4 Possuir diploma de nível superior, reconhecido na for- } \\
\text { ma da legislação brasileira }\end{array}$ \\
\hline $062 / 2010$ & $\begin{array}{l}\text { 2.1.4 Possuir diploma de nível superior, reconhecido na for- } \\
\text { ma da legislação brasileira }\end{array}$ \\
\hline $029 / 2011$ & $\begin{array}{l}\text { 2.1.5 Possuir diploma de nível superior, reconhecido na for- } \\
\text { ma da legislação brasileira }\end{array}$ \\
\hline $039 / 2012$ & $\begin{array}{l}\text { 2.1.6 Possuir diploma de nível superior, reconhecido na for- } \\
\text { ma da legislação brasileira }\end{array}$ \\
\hline $044 / 2013$ & $\begin{array}{l}\text { 2.1.5 Possuir diploma de nível superior, reconhecido na for- } \\
\text { ma da legislação brasileira }\end{array}$ \\
\hline $52 / 2014$ & $\begin{array}{l}\text { 2.1.5 Possuir diploma de nível superior na área indicada pela } \\
\text { instituição estrangeira (ANEXO I), reconhecido na forma da } \\
\text { legislação brasileira }\end{array}$ \\
\hline
\end{tabular}

Fonte: elaborado pela autora.

Não é difícil verificar que a exigência é abrangente e, até 2013, baseada na necessidade exclusiva de que o diploma do candidato fosse "reconhecido na forma da legislação brasileira". Perceba-se que, somente em 2014, o quadro sofre alteração, indicando que diferentes áreas de formação poderiam ser especificamente exigidas pelas universidades estrangeiras. 
O fato de 78,5\% (33 dentre 42) dos leitores estudados terem o curso de Letras como formação inicial e dois terem dupla formação (em Letras e em outro curso) mostra, entretanto, que essa carreira é uma tendência relativa ao perfil profissional do universo estudado. Por outro lado, os editais não apresentarem exigência relativa à formação nessa área, parece corroborar os dados obtidos por Baptista et al. (2009), em estudo relativo à história do leitorado português.

Segundo esses autores, até meados dos anos de 1980, quem se tornava leitor do governo português, bem como o país em que iria atuar, era uma questão de destino. $\mathrm{O}$ estudo desenvolvido por eles apontou que ser leitor era, portanto, "obra do acaso e das circunstâncias da vida dos indivíduos e das instituições", pois "bastava falar português, possuir uma certa cultura geral, de que o grau académico em qualquer área do conhecimento era garantia, e ter interesse pela cultura, pela literatura, pela língua" (BAPTISTA et al., obra citada, p. 94).

Quando se considera que o Programa de Leitorado é uma política central na diplomacia brasileira, parece altamente questionável não exigir uma formação específica e contundente na área de Estudos da Linguagem. Diz-se que a política é central não apenas por ser uma das responsáveis pela expansão da língua e da cultura nacionais, mas por atuar no sentido de divulgar imagens coerentes do país e por enfatizar o seu funcionamento em locais estratégicos à formação de futuros atuantes em diversas áreas do mundo do trabalho e, consequentemente, do girar da economia brasileira e daquela ligada à língua portuguesa de forma mais ampla.

Em relação à titulação e à formação continuada estabelecida por meio de cursos de especialização, mestrado, doutorado e pós-doutorado, os dados mostraram que os leitores pesquisados são profissionais que buscam os altos níveis da academia. A partir dos dados apresentados por cada um dos sujeitos, em seu Lattes e LinkedIn, até o fim da pesquisa (em janeiro de 2015), foi possível observar que somente dois leitores possuem apenas graduação e que a grande maioria, em contrapartida, já é mestre, conforme pode ser observado no gráfico II: 
Gráfico II - Títulos obtidos pelos leitores até o início da pesquisa

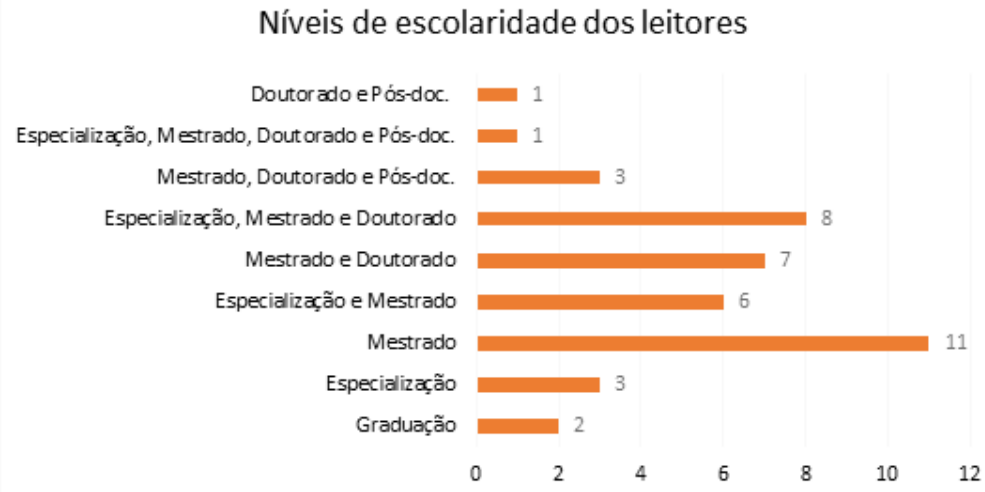

Fonte: elaborado pela autora.

Quanto ao desenvolvimento dos cursos de pós-graduação, constatou-se que boa parte dos leitores fez doutorado com período sanduíche e/ou cursou mestrados e/ou doutorados plenos fora do Brasil. Esses apontamentos são particularmente relevantes por apresentarem uma outra tendência ligada ao perfil profissional dos leitores estudados: dentre aqueles que possuem qualquer título de pós-graduação, os quais totalizam o número de quarenta dentre quarenta e dois profissionais, dezenove o adquiriu em instituições estrangeiras e/ou com período de estágio internacional.

Dentre esses casos, notou-se que três leitores foram alunos de especialização, mestrado e/ou doutorado nos mesmos países em que posteriormente atuaram como leitores, porém em instituições diferentes daquelas em que assumiram os postos de Leitorado. Em contrapartida, outros dez leitores cursaram a pós-graduação nas mesmas instituições em que, algum tempo depois, se tornaram leitores do governo brasileiro.

Quanto às exigências ligadas à formação universitária em nível de pós-graduação, os editais do Programa de Leitorado passaram por algumas modificações entre os anos de 2010 e 2014, conforme é possível observar pelo quadro $\mathrm{II}^{8}$ : 
Quadro II - Requisitos para a candidatura dos leitores, em relação à pós-graduação, segundo os editais de seleção dos anos de 2010 a 2014.

\begin{tabular}{|c|c|}
\hline Edital no. & $\begin{array}{l}\text { Requisitos para candidatura em relação à pós-gradu- } \\
\text { ação } \\
\text { (item e exigência) }\end{array}$ \\
\hline $023 / 2010$ & Sem requisitos \\
\hline $062 / 2010$ & Sem requisitos \\
\hline $029 / 2011$ & $\begin{array}{l}\text { 2.1.7 Possuir formação acadêmica e experiência no } \\
\text { ensino de linguística, teoria literária, literatura, bra- } \\
\text { sileira, cultura brasileira, política cultural, ciências } \\
\text { sociais, ciência política ou relações internacionais, a } \\
\text { depender das especificidades de cada vaga }\end{array}$ \\
\hline $039 / 2012$ & $\begin{array}{l}\text { 2.1.8 Possuir formação acadêmica (doutorado ou } \\
\text { mestrado) e experiência no ensino de linguística, lin- } \\
\text { guística aplicada, literatura brasileira, cultura brasilei- } \\
\text { ra, ou outras áreas, conforme indicado pela instituição } \\
\text { estrangeira }\end{array}$ \\
\hline $044 / 2013$ & $\begin{array}{l}\text { 2.1.7 Possuir formação acadêmica (doutorado ou } \\
\text { mestrado) e experiência no ensino de linguística, lin- } \\
\text { guística aplicada, literatura brasileira, cultura brasilei- } \\
\text { ra, ou outras áreas, conforme indicado pela instituição } \\
\text { estrangeira }\end{array}$ \\
\hline $52 / 2014$ & $\begin{array}{l}\text { 2.1.8 Possuir formação acadêmica (doutorado ou } \\
\text { mestrado) e experiência no ensino de linguística, lin- } \\
\text { guística aplicada, literatura brasileira, cultura brasilei- } \\
\text { ra, ou outras áreas, conforme indicado pela instituição } \\
\text { estrangeira }\end{array}$ \\
\hline
\end{tabular}

Fonte: elaborado pela autora.

Em 2010, os editais não apresentaram requisito algum, de modo que, somente a partir de 2011, algumas áreas do domínio acadêmico tor- 
nam-se constantes como exigências - este é o caso de Linguística, Literatura Brasileira e Cultura Brasileira. Observe-se, contudo, que o edital de 2011 também acrescenta, entre as possibilidades de formação, Política Cultural, Ciências Sociais, Ciência Política e Relações Internacionais, não restringindo os candidatos, por assim ser, a especializações ligadas aos estudos da linguagem. Note-se que a Linguística Aplicada torna-se uma constante, como área de formação admitida, a partir de 2012, mas a expressão "outras áreas, conforme indicado pela instituição estrangeira" passa conjuntamente a generalizar as possibilidades.

No tocante aos leitores estudados, as áreas de concentração escolhidas para os cursos de pós-graduação foram: Linguística, Letras, Estudos da Linguagem, Linguística Aplicada, Filologia, Estudos Literários, Educação (incluindo Psicopedagogia), Mídias, Estudos Brasileiros, Estudos Interculturais, Filosofia, História, Ciência Política, Antropologia e Administração - sendo Estudos da Linguagem, Linguística, Letras e Literatura as áreas mais recorrentes entre os leitores estudados.

No que diz respeito a uma formação específica para o ensino de português para falantes de outras línguas $(\mathrm{PFOL})^{9}$, um questionário aplicado via e-mail permitiu o recolhimento de dados referentes a $72 \%$ do universo de leitores estudados, visto que trinta deles o responderam. Sendo assim, uma de suas perguntas foi: "[e]m sua formação inicial ou continuada, você participou de alguma disciplina ou curso relacionado ao ensino de português para falantes de outras línguas? Comente."

A partir dela, quatorze leitores responderam que não participaram de qualquer curso que envolvesse a didática de PFOL, alegando que essa foi uma lacuna apresentada pelos cursos de graduação e de pós-graduação que fizeram e/ou que desconheciam a oferta da temática por parte das universidades nacionais.

Uma única leitora indicou ter se formado em Letras com habilitação específica em Português do Brasil como Segunda Língua. Os outros quinze leitores, isto é, $52 \%$ dos que responderam ao questionário, afirmaram que a pesquisa, a participação em eventos e/ou disciplinas isoladas de graduação e de pós-graduação é que estabeleceram a sua relação com a formalização de conteúdos ligados aos modos de ensinar e aprender $\mathrm{PFOL}^{10}$ :

Minha formação acadêmica (graduação, mestrado e doutorado) é voltada pala a área de ensino-aprendizagem de Língua Estrangeira, em especial, PLE. [Antigo(a) Leitor(a) L4 do governo brasileiro] 
Meu tema de mestrado foi a avaliação oral do Celpe-bras, fiz uma disciplina sobre PLE e agora no doutorado faço outra disciplina sobre ensino e pesquisa em PLE. [Antigo(a) Leitor(a) L23 do governo brasileiro]

Minha graduação foi específica no ensino de línguas estrangeiras. Além disso, tenho mestrado específico em PLE e fiz mini-cursos e workshops específicos para o ensino de L2, LE ou LA. [Antigo(a) Leitor(a) L3 do governo brasileiro]

Sim, minha formação em Letras teve e tem papel crucial no meu desenvolvimento profissional. Durante a graduação, fiz uma disciplina voltada a PLE e, durante meu período fora do Brasil, assisti a Congressos e fiz cursos de formação voltados para a área. [Antigo(a) Leitor(a) L17 do governo brasileiro]

Durante o mestrado, cursei uma disciplina sobre letramento entre cujos tópicos havia o ensino de língua materna e língua estrangeira. Entre os seminários realizados, existiram alguns focados no ensino de Português como língua estrangeira, assim como o de Inglês como língua estrangeira ou segunda língua. Esta disciplina foi-me importante para fornecer um aparato teórico-metodológico para o ensino de PLE. [Antigo(a) Leitor(a) L21 do governo brasileiro]

Como a minha formação é em Letras - Inglês, cursei disciplinas na graduação sobre o ensino de línguas estrangeiras (naturalmente, com o foco em inglês) e disciplinas de revisão de textos em língua portuguesa. Quando estava no país X, participei de um curso para formação de professores na região $Y$, que durou uma semana, com o professor Dr. José Carlos de Almeida Filho. [Antigo(a) Leitor(a) L13 do governo brasileiro]

Disciplina, não, entretanto, participei, no terceiro e quarto anos da Graduação, de um Projeto de Ensino - o ENPFOL, nesta vertente, coordenado pela Prof. Viviane Bagio Furtoso, na universidade X. [Antigo(a) Leitor(a) L7 do governo brasileiro]

Diferentes estudos (FURTOSO, 2001; AMADO, 2008) apontaram o quanto é rara a oferta brasileira de licenciaturas destinadas à formação específica de professores de PFOL. Sem dúvidas, essa realidade justifica o baixo índice de leitores que possuem formação na área, o que nos leva a considerar que esta é uma das necessidades não só da área de Letras, mas também do Programa de Leitorado. 
Assim, a sequência do texto destina-se a uma breve discussão ligada à formação de professores de línguas no Brasil, bem como à defesa de um perfil profissional para o leitor, o que se dá em consideração à ideia de que internacionalizar a língua do Brasil só pode ocorrer, em termos de ensino, mediante a profisssionalização docente.

4. Leitor brasileiro e a formação de professores de línguas: algumas proposições em prol da profissionalização docente

Na década de 1930, concebia-se, então, que o professor de línguas brasileiro poderia ser formado por meio de um modelo baseado na racionalidade técnica. Logo, ele seria um aplicador rigoroso de técnicas aprendidas durante o tempo de instrução universitária, conforme habilitações fechadas em suas especificidades. Os problemas de sala de aula seriam resolvidos a partir da racionalidade científica, de modo que teoria e prática andavam separadas na preparação profissional. A prática não careceria de princípios epistemológicos específicos, sendo, portanto, uma mera aplicação de conhecimentos teóricos.

Enfatizada nos cursos de formação de professores de línguas, sobretudo na década de 1980, essa maneira de formar compreendia que um bom professor era aquele que dominava os conhecimentos relativos à língua que iria ministrar e, embora tenha sido muito criticada, permaneceu, durante muito tempo, como o carro-chefe de boa parte das universidades brasileiras (PEREIRA, 1999).

Na sequência desse quadro, a literatura especializada propôs o modelo de racionalidade prática, o qual também ganhou espaço na formação dos professores de língua portuguesa. A partir dele, o professor foi considerado como um profissional autônomo e reflexivo quanto à sua prática. Assim, a prática tornou-se o centro da formação e entendeu-se que é a partir dela que os conhecimentos devem ser gerados. Visto como outra camisa de força, entretanto, esse tipo de formação desconsidera a importância da teoria e aprisiona alguns professores brasileiros a um conhecimento que não passa pelo crivo dos grandes teóricos (PEREIRA, 1999).

Aos poucos, porém, a ciência viu surgir a abordagem do professor reflexivo, a qual, sobretudo a partir de pesquisas realizadas pelos linguistas aplicados da década de 1990, levou o processo de formar professores de línguas no Brasil à aquisição de características mais críticas. Principal- 
mente a partir do proposto por Donald Schön (2000), entendeu-se que a acumulação de conteúdos ou a prática em isolamento não eram suficientes para a profissionalização docente. Antes, a prática deveria fornecer subsídios para a criação das bases teóricas.

Nessa linha de formação de professores, o que se pretende é retirar a centralidade da técnica e apresentar alternativas que permitam colocar o profissional das línguas em contato com as questões políticas e ideológicas da sociedade. Assim, entende-se que a formação passa por processos

essenciais e complexos, relativos, mutáveis, com valores ético-políticos e atravessados pelas questões socioculturais das sociedades (...). Desse modo, a construção dos saberes está diretamente ligada ao contexto social, ao tempo, às condições materiais e aos aspectos sócio-histórico-culturais que fazem parte integrante do processo pedagógico (BENEVIDES, 2005, p. 88).

Como resultado de iniciativas tão recentes, não é espantoso dizer que a formação de professores só adquiriu uma posição de centralidade, na pesquisa acadêmica, a partir dos últimos trinta anos e, mais especificamente, na última década do século XX. Desde então, o professor tem sido visto como sujeito social e como parte essencial do processo de aquisição e aprendizagem do português ou de qualquer outro idioma materno ou estrangeiro.

Assim, viu-se que ele é formado a partir de uma sistemática que, quando pensada globalmente, abarca múltiplos fatores que ainda carecem de reflexão na atualidade, sobretudo se as seguintes perguntas forem impostas: qual é o professor de línguas/de PFOL que se forma? Qual se deseja formar? Para quais objetivos? Mediante qual currículo?

Sabe-se que a qualificação profissional do professor, além de ser dependente de formação acadêmica (inicial ou continuada) na área, está ligada ao exercício da função, à aquisição de habilidades pedagógicas, dentre outros quesitos que são definidos como prioritários a cada contexto e segundo os imperativos estabelecidos por cada instituição de ensino, ou ainda, pelo país e por suas políticas educacionais, ou mesmo pela organização empresarial em que atua o professor etc. (CASTELLOTTI; DE CARLO, 1995).

Nesse sentido, Almeida Filho (2005) sugeriu, em uma das primeiras publicações brasileiras voltadas especificamente para a formação do professor de línguas, que era necessário aperfeiçoar quadros docentes para a sociedade da modernidade tardia. Sob seu ponto de vista, os professores deveriam ser formados como sujeitos que pensam e agem a partir de competências intercomplementares. 
A criação de um perfil profissional apresenta-se, assim, como o resultado de muitos fatores em interação, iniciando pelo conhecimento teórico fornecido pela formação inicial - dos ambientes universitários, passando pela prática e chegando sempre à capacidade reflexiva. A "formação tem sido descrita como uma preparação mais complexa do professor, envolvendo a fusão do conhecimento recebido com o conhecimento experimental e uma reflexão sobre esses dois tipos de conhecimento" (LEFFA, 2008, p. 355).

Conforme sugerido, ainda é bastante rara, no Brasil, a oferta de cursos direcionados à formação de professores aptos a ensinar PFOL. Para criar a dimensão disso, entenda-se que algumas universidades discutem a temática apenas por meio de algumas disciplinas registradas no catálogo de graduação e pós-graduação da área de Letras e/ou Linguística Aplicada: tal é o caso da USP, UFBA, UFJF e UFMG.

A UNICAMP e a UnB são, por outro lado, as instituições que, com exclusividade, oferecem um curso de graduação em Letras - Português como L2/LE e Letras - Português do Brasil como Segunda Língua respectivamente. A PUC-Rio, por sua vez, liga-se à área mediante a manutenção de um curso de pós-graduação latu sensu - Formação de Professores de Português para Estrangeiros (FURTOSO, 2001; OLIVEIRA, 2017).

Esta realidade permite considerar, em primeiro lugar e obviamente, que as ofertas de formação na área carecem de ampliação. Dado o fato de que o Português do Brasil é uma língua de projeção internacional e que há demanda pela sua aprendizagem, torna-se importante que os futuros professores recebam formação específica na área. Não obstante, a raridade da formação também torna inviável que, nas atuais conjunturas, ela venha a ser uma das exigências dos editais de seleção do Programa de Leitorado.

Ao lado disso, porém, a discussão anterior mostra que ser professor de línguas não diz respeito a "dom" ou a um exercício profissional simplista e que pode se dar em caráter de improviso. Trata-se, na verdade, de receber formação específica e complexa, ligada a teorias diversas, bem como a treinamento relacionado às situações e significados que tangenciam a ação de ensinar línguas na contemporaneidade.

Antes de ceder espaço às considerações finais, esta seção do artigo é finalizada com a afirmação de que o leitor brasileiro deve ser um profissional do ensino de línguas. Permitir que ele seja formado em áreas que não as Letras ou a Linguística não é compatível com o objetivo que o próprio MRE estabeleceu como central ao programa: "promover a língua portugue- 
sa, em sua vertente brasileira, além da cultura, literatura e estudos brasileiros" ${ }^{\prime 11}$ em Instituições de Ensino Superior Estrangeiras. Visto que o idioma nacional aparece em primeiro lugar, enquanto a cultura relativa às letras e à sociedade brasileira surge somente na sequência frasal, os editais necessitam de reconfiguração e de estreitamento relativo à institucionalização do perfil profissional que virá a ser exigido dos futuros leitores.

\section{Considerações finais}

Dado o objetivo estabelecido para este artigo, as discussões permitiram verificar que a formação inicial dos leitores ocorre predominantemente, embora não apenas, nas Letras. Em geral, eles são profissionais da área de linguagem, atuantes no domínio da língua portuguesa e de suas literaturas, e/ou de línguas estrangeiras e de suas literaturas. Quanto à formação continuada, notou-se também uma predominância de formação na grande área de Letras e suas subáreas - Linguística, Linguística Aplicada e Literatura.

O grau de instrução dos sujeitos estudados mostrou-se alto: compreendido majoritariamente entre mestrado concluído e doutorado em andamento - fato revelador de que os leitores possuem um perfil profissional marcado pela formação continuada e por uma iniciativa voltada à especialização.

Os dados, por outro lado, também mostraram que não são muitos os leitores com formação específica na área de PFOL, o que parece pouco coerente com a proposta política do Programa de Leitorado. Como discutido, entretanto, tal realidade se deve a uma oferta ainda tímida, no contexto brasileiro, de cursos voltados para esse tipo de formação.

Logo, os dados apontam a existência de uma carência ligada à ampliação de oportunidades formativas que qualifiquem os profissionais especificamente para o ensino da língua e da cultura nacionais a falantes de outros idiomas. Entretanto, eles levam igualmente à defesa de que a profissionalização do docente de línguas é uma necessidade e que, assim sendo, a formação na área deve vir a se tornar uma das exigências dos editais que selecionam leitores brasileiros. 


\section{BRAZIL'S PROGRAMA DE LEITORADO: discussions on the professional profile of lectureship}

\section{ABSTRACT}

In the context of studies on external language policies (CALVET, 2007), this article proposes to present an analysis of the professional profile, in terms of academic training, of subjects who worked with the Programa de Leitorado between 2010 and 2014. For this, unprecedented data, collected through documental examination in the Arquivo Nacional of the Palácio do Itamaraty, are presented and discussed. Information obtained through the application of a questionnaire to the studied lectureships and an interview with the former minister-director of the Departamento Cultural of the Ministério das Relações Exteriores, are also part of the problematization and allow to relate the formation of the lectureships to a broader discussion about the professionalization of the language teacher in Brazil. From this, the study also mentions the low supply of degrees in the area of Portuguese Language/ Portuguese to Speakers of Other Languages (PFOL in Portuguese) and the lack of demand, by Capes and the Ministério das Relações Exteriores, for a specific training in Portuguese Language to apply for the Programa de Leitorado, which allows to emphasize, with a view to the future progress of this linguistic planning, that the lectureships must be teachers/professionals trained in the area of languages.

KEYWORDS: Lectureships; Linguistic Policies; Brazil.

\section{NOTAS}

\footnotetext{
${ }^{1}$ Neste artigo, adota-se a visão teórica de Calvet (2007, p.11), já que o autor diferencia os termos política linguística e planejamento linguístico. Segundo o sociolinguista francês, planejamentos se referem às implementações/aplicações/execuções
} 
de decisões tomadas no âmbito das políticas das línguas - conceito que engloba as "grandes decisões referentes às relações entre as línguas e as sociedades".

${ }^{2}$ Sobre isso, é importante frisar que o critério para a seleção dos leitores pesquisados foi de que os sujeitos tivessem trabalhado para o MRE entre 2010 e 2014. Porém, era indiferente se esse trabalho começou antes ou terminou após o período cronológico estabelecido. A seleção temporal ocorreu em função de ser um período longo e que poderia gerar dados consistentes, além de justificar-se pela data em que os dados foram coletados, pela autora do presente artigo, no Arquivo Nacional do Palácio do Itamaraty: novembro de 2014.

${ }^{3}$ Os dados coletados referem-se a relatórios oficiais que são semestralmente enviados, pelos leitores, ao Ministério das Relações Exteriores. Eles foram obtidos, em novembro de 2014, no Palácio do Itamaraty. Na ocasião, a autora foi recebida pelo ex-ministro George Torquato Firmeza, pelo diplomata João Domingos Batiston Bimbato e pela oficial de chancelaria Rose Marie Romariz Maasri, os quais forneceram acesso a mais de setecentas páginas dos referidos documentos.

${ }^{4}$ Sobre isso, em entrevista à autora do estudo, o ministro George Torquato Firmeza relatou que as relações internacionais prioritárias ao Departamento Cultural do Itamaraty referiam-se, à altura da coleta de dados, aos países que compõem a CPLP (Comunidade dos Países de Língua Portuguesa), aos BRICS (Brasil, Rússia, Índia, China e África do Sul), ao Mercosul. e àqueles de elevada importância para o Programa Ciência sem Fronteiras (sobretudo Estados Unidos da América, Alemanha e Espanha - dado o elevado número de estudantes que foram enviados pelo governo brasileiro a esses países).

${ }^{5}$ De acordo com o Decreto n. ${ }^{\circ} 6.170$, de 25 de julho de 2007, o regime de convênio consiste em "acordo, ajuste ou qualquer outro instrumento que discipline a transferência de recursos financeiros de dotações consignadas nos Orçamentos Fiscal e da Seguridade Social da União e tenha como partícipe, de um lado, órgão ou entidade da administração pública federal, direta ou indireta, e, de outro lado, órgão ou entidade da administração pública estadual, distrital ou municipal, direta ou indireta, ou ainda, entidades privadas sem fins lucrativos, visando a execução de programa de governo, envolvendo a realização de projeto, atividade, serviço, aquisição de bens ou evento de interesse recíproco, em regime de mútua cooperação" (BRASIL,2007). Informações disponíveis em http://www.planalto.gov.br/ ccivil_03/_ato2007-2010/2007/decreto/d6170.htm Acesso em: 02 out. 2017.

${ }^{6}$ Informações disponíveis em: http://www.capes.gov.br/cooperacao-internacional/multinacional/programa-leitorado Acesso em: 20 out. 2017.

${ }^{7}$ Para leitura completa dos editais: http://www.capes.gov.br/cooperacao-internacional/multinacional/programa-leitorado Acesso em: 07 dez. 2017. 
${ }^{8}$ Para leitura completa dos editais: http://www.capes.gov.br/cooperacao-internacional/multinacional/programa-leitorado $\mathrm{O}$ referido site permite localizar editais não contemplados pelo período temporal selecionado nessa pesquisa, a saber: um edital de 2008 e dois de 2009. Em todos os casos, pode-se verificar que o Itamaraty, em parceria com a Capes, também não apresentou requisitos para candidatura ligados à titulação em nível de pós-graduação e/ou à área do conhecimento. Acesso em: 08 dez. 2017.

${ }^{9}$ PFOL foi uma sigla cunhada para utilização sociolinguística, já que inicialmente voltada ao âmbito de estudos relativos a indígenas brasileiros que, sendo falantes de suas línguas nativas, aprendem o português como idioma não materno. Aos poucos, entretanto, a utilização de PFOL tornou-se mais abrangente, de modo a abarcar todos os sujeitos, falantes de outros idiomas, que optam pela aprendizagem do português.

${ }^{10}$ Para garantir o anonimato dos participantes, quaisquer informações relacionadas a eles ou à sua vida acadêmica foram substituídas por termos como universidade $x$, país $x$, etc.

${ }^{11}$ Informações disponíveis no site da Capes: http://www.capes.gov.br/cooperacao-internacional/multinacional/programa-leitorado Acesso em: 06 mai. 2018.

BRAZIL'S PROGRAMA DE LEITORADO: discussions on the professional profile of lectureship

\section{REFERÊNCIAS}

ALMEIDA FILHO, José Carlos Paes de. O professor de Língua Estrangeira em Formação. Campinas: Pontes, $2^{\mathrm{a}}$ ed., 2005. 184 p.

AMADO, Rosane de Sá. O ensino e a pesquisa de português para falantes de outras línguas. Revista Guavira, Três Lagoas, n. ${ }^{\circ}$ 06, p. 67-75, 2008. Disponível em: http://scholar.googleusercontent.com/scholar?q=cache:ezWyOkjQ1RMJ:sch olar.google.com $/+$ portugu $\% \mathrm{C} 3 \% \mathrm{AAs}+$ para + falantes + de + outras $+1 \% \mathrm{C} 3 \% \mathrm{ADn} g u$ as\&hl=pt-BR\&as_sdt=0,5 Acesso em: 30 ago. 2017.

BAPTISTA, Luís V.; COSTA, João; PEREIRA, Patrícia (Orgs.). O mundo dos Leitorados: políticas e práticas de internacionalização da língua portuguesa. Lisboa: Edições Colibri, 2009.

BENEVIDES, Araceli Sobreira. A leitura e a formação docente: a trajetória da prática da leitura de alunos/as do curso de Letras. Programa de Pós-Graduação em Educação. 378f. Tese (Doutorado em Educação) - Universidade Federal 
do Rio Grande do Norte, Natal. 2005.

BRASIL. Ministério das Relações Exteriores. Gabinete do Ministro. Portaria n. ${ }^{\circ}$ 2, de 29 de março de 1999. Diário Oficial da União, Brasília, DF, 01 abr. 1999, Seção 1. Disponível em: http://www.jusbrasil.com.br/diarios/1097638/dou-secao-1-01-04- 1999-pg-29 Acesso em: 09 set. 2017.

. Ministério da Educação. Portaria n. ${ }^{0}$ 4.056. Brasília, 2005. Disponível em: http://portal.mec.gov.br/sesu/arquivos/pdf/portarias/portariacolip-4056.pdf Acesso em: 09 jun. 2016.

. Ministério das Relações Exteriores. Gabinete do Ministro. Portaria Interministerial $\mathbf{n}^{0}$ 01, de 20 de março 2006. Diário Oficial da União, Brasília, DF, 22 mar. 2006, 2006, Seção 1, p. 28. Disponível em: http://www.jusbrasil.com.br/ diarios/505063/pg-28-secao-1-diario-oficial-da-uniao-dou-de-22-03-2006 Acesso em: 09 set. 2017.

. Presidência da República. Casa Civil. Decreto n. ${ }^{\mathbf{8}} \mathbf{8 . 1 8 0}$, de 30 de dezembro de 2013. Brasília, 2013. Disponível em: http://www.planalto.gov.br/ccivil 03/Ato2011-2014/2013/Decreto/D8180.htm Acesso em: 09 set. 2017.

BRUCHET, Raphaël. Le lecteur de français: un acteur essentiel au cœur de la coopération linguistique, culturelle et universitaire. Synergies Espagne, $\mathrm{n}^{\circ} 5$, p. 227-242, 2012. Disponível em: http://gerflint.fr/Base/Espagne5/bruchet.pdf Acesso em: 21 nov. 2017.

CALVET, Louis-Jean. As políticas linguísticas. São Paulo: Parábola Editorial, 2007. 166 p.

CASTELLOTTI, Véronique; DE CARLO, Maddalena. Le formation des enseignants de langue. Paris: CLE Internacional, 1995. 192 p.

DINIZ, Leandro Rodrigues Alves. Política linguística do Estado brasileiro na contemporaneidade: a institucionalização de mecanismos de promoção da língua nacional no exterior. 378f. Tese (Doutorado em Linguística) - Universidade Estadual de Campinas, Campinas. 2012.

FERREIRA, Laura Márcia Luiza. O leitorado brasileiro na Tailândia: uma contribuição para o debate a respeito do papel do professor-leitor. Revista do GEL, v. 11, n. 1, p. 10-29, 2014. Disponível em: https://revistadogel.gel.org.br/rg/article/ viewFile/17/274 Acesso em: 14 ago. 2017.

FIORIN, José Luiz. A criação dos cursos de letras no Brasil e as primeiras orientações da pesquisa linguística universitária. Revista Língua \& Letras, v. 7, n. ${ }^{\circ}$ 12, p. 11-25, $1^{\text {o }}$ sem. 2006.Disponível em: http://e-revista.unioeste.br/index.php/ linguaseletras/article/view/887/752 Acesso em: 14 ago. 2017.

FURTOSO, Viviane Aparecida Bagio. Português para falantes de outras lín- 
guas: aspectos para a formação do professor. Dissertação (Mestrado em Linguística) - Universidade Estadual de Londrina, Londrina, 2001.

LEFFA, Vilson J. O professor de línguas estrangeiras: construindo a profissão. Pelotas: Educat, $2^{\text {a }}$ ed., 2008.

NÓBREGA, Maria Helena. Políticas linguísticas e internacionalização da língua portuguesa: desafios para a inovação. Revista de Estudos da Linguagem, v. 24, p. 417-445, 2016. Disponível em: http://periodicos.letras.ufmg.br/index.php/relin/article/view/8603 Acesso em: 10 abr. 2017.

OLIVEIRA, Gilvan Müller. O lugar das línguas: A América do Sul e os mercados linguísticos na Nova Economia. Synergies Brésil, nº 1, p. 21-30, 2010. Disponível em: http://gerflint.fr/Base/BresilSPECIAL1/gilvan.pdf Acesso em: 20 ago. 2017.

PEREIRA, Júlio Emílio Diniz. As licenciaturas e as novas políticas educacionais para a formação docente. Educação \& Sociedade, ano XX, nº 68, Dez./99. Disponível em: http://www.scielo.br/pdf/es/v20n68/a06v2068 Acesso em: 27 ago. 2017. SÁ, Daniel Serravalle. O leitorado brasileiro em Manchester: política linguística e ensino de português como língua estrangeira. Cadernos de Letras da

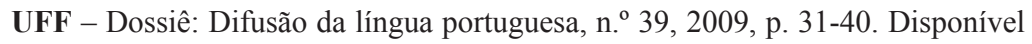
em: http://api.ning.com/files/6sTIkUNHiRTL*IvYoORCf1vSLDBTwW-oxaZ-P4dHwvrI5RQSI4x*ExXNrgAYMpt-5uP-Ue810bisbiUu5w*1RVdFK6fPu6ox/ artigo1.pdf Acesso em: 10 out. 2017.

SCHÖN, Donald A. Educando o profissional reflexivo. Porto Alegre: Artes Médicas Sul, 2000.

Recebido: 11/05/2018

Aceito: $14 / 09 / 2018$ 